\title{
The external and internal measurement impact on shear modulus distribution within cyclic small strains in triaxal studies into cohesive soil
}

\author{
M. Jastrzebska ${ }^{1, \text { a }}$ \\ ${ }^{1}$ Silesian University of Technology, 44-100Gliwice, ul. Akademicka 5/214, Poland
}

\begin{abstract}
The paper deals with comparison of tangent shear moduli $G_{s}$ of kaolin from Tułowice obtained from cyclic triaxial tests on the basis of external and internal reading in the small strains range $\left(10^{-5} \div 10^{-3}\right)$. The tests were carried out on a modernised test bed, enabling full saturation of specimens using the back pressure method as well as a precise internal measurement of strains by means of contactless microdisplacements sensors. The value of linearity factor $L$ is one of adopted quality criteria for two measuring methods. Maintaining a constant deformation rate the influence of various cyclic process parameters (deviator stress amplitude - constant or variable; high or low; initial level of stress and strain, at which the unloading and reloading cycles were started; overconsolidation ratio OCR as well as cycles' number and arrangement) on the „shear modulus - axial strain" characteristic was studied. The obtained values of $G_{\text {int }}$ and $G_{\text {ext }}$ (or $L_{\text {int }}$ and $L_{\text {ext }}$ ) clearly show an underestimation (even 5 times) of $G_{s}$ value within the range $10^{-5} \div 10^{-3}$ when using an external measurement. In addition, the differences between $G_{i n t}$ and $G_{e x t}$, which develop differently depending on specified cyclic process parameters, gradually decrease with increasing axial strains.
\end{abstract}

\section{Issues of small strains and cohesive soils behaviour under cyclic loading}

\subsection{Preliminary comments}

A reliable determination of relationships between stress and strain is the foundation of safe designing of service states. The accomplishment of this task in the case of soils on the basis of laboratory tests results should proceed under full control of boundary conditions for fields of effective strain and stress and conditions of pore drainage.

A dynamic development, which occurred in this field in mid-eighties, not only improved the quality of tests carried out, but also contributed to discovering very strong physical nonlinearity of the soil environment in the small strains range $\left(10^{-5} \div 10^{-3}\right)$. The nonlinearity referred to manifests in a dozen or so times decline of shear modulus $G$ in the range considered. Settlements predicted without taking into account the above phenomenon happen to be drastically overestimated, in

\footnotetext{
a e-mail : malgorzata.jastrzebska@ polsl.pl
} 
particular when the pressure from the foundation on the soil is relatively small, what usually happens in the case of buildings of extensive plans (Kriegel and Weisner, [1]; Burland, [2]). It is characteristic and surprising at the same time that a general advancement of studies on small strains does not translate into the case of cyclic loading commonly existing in nature and technology. Even in so representative and avant-garde publication as Jardine's paper [3], only one „loading unloading" cycle is considered. So it has been recognised that if both the phenomena in the area of small deformations and the processes of soils response to cyclic loads play crucial role in geotechnical designing and contracting then it may be expected that the effect of their combined occurrence will be even more significant.

\subsection{Cohesive soil stiffness in undrained triaxial tests acc. to external and internal readings}

Issues related to the influence of measurement type (internal or external) in undrained triaxial tests on the value of Young's modulus E may be found inter alia in Rampello's paper [4]. The tests were carried out at various values of average effective pressure and on three different levels of axial strains: $0.00005,0.0001$ and 0.001 . The considerations comprised undisturbed and swollen specimens. Results of tests in a resonance column were additionally analysed. Results obtained by Rampello confirmed previous results obtained by Rampello and Pane [5], Georgiannou et al. [6], Costafilho [7], Daramola [8], namely that the stiffness - in undrained triaxial conditions - from internal measurements is always higher, but the differences diminish with increasing axial strains. Higher discrepancies were observed in turn in the case of tests without consolidation and undrained (UU). In their case external measurements give erroneous indications of linear behaviour of soils in the area of small strains. The stiffness for swollen specimens turns out less underestimated than for undisturbed specimens, where the linearity factor $L$ suggested by Jardine (Jardine et al., [9]) in the form (1):

$$
L=\frac{E_{10^{3}}}{E_{10^{4}}}
$$

seems to be constant for each of them $\left(\begin{array}{ll}L & 0.33\end{array}\right)$.

Comparisons of results between static (triaxial apparatus) and dynamic (resonance column) tests have shown a small advantage of the latter, which seems to grow slightly with increasing strains. In turn, linearity factors for the two different types of tests remain in quite good agreement $\left(L_{R C}=L_{T X i n t}\right.$

$0.34)$.

\section{Cyclic triaxial tests}

\subsection{Laboratory equipment description}

A conventional triaxial apparatus has been used to perform tests on kaolin samples. The triaxial cell contains internal tie bars and a rigid connection between the top cap and the loading piston. The diameters of top cap and pedestal are equal to that of the sample. Strips of filter paper along the sample and porous stones screwed on the top cap and bottom base were used for drainage. The pressure cell was filled with de-aerated water.

Two different measurements of axial strain $l$ were taken:

- Internal 1 on the lateral surface of the specimen using two couples of high resolution submergible proximity transducers. The transducers were mounted at two positions, opposite to each other, around the specimen diameter. The range and resolution of these transducers are $2.0 \mathrm{~mm}$ and $0.01 \%$, respectively.

- External ${ }_{l}$ using the external displacement gauge fixed on the loading piston. 
Lateral strain ${ }_{3}$ was directly and locally measured by means of a couple of proximity transducers placed in the central part of the sample. A piece of thin aluminium foil was used as a target. This target was attached to the external membrane with silicone grease.

The data reading took place at chosen time intervals.

\subsection{Material and samples preparation for triaxial compression}

The material used in this study comes from the Porcelain Factory in Tułowice. Its basic properties are given in Table 1 (Jastrzębska, [10]). The tested soil exhibited great homogeneity of structure. In all cases the samples for triaxial tests were made on a soil paste of $w 50 \%$ water content (what makes around $1.2 w_{L}$ ), which was initially consolidated at isotropic pressure equal to $80 \mathrm{kPa}$. The adopted minimum values of initial consolidating pressure were dictated by obtaining the sample ultimately in such a state as it would be possible to cut out from it a proper specimen without the fear of losing its shape during the preparation and placing in the test cell. Finally all triaxial tests were carried out on samples $50 \mathrm{~mm}$ in diameter, $100 \mathrm{~mm}$ high. Each sample was saturated. At first they were flushed with de-aerated water. Thereafter a high back pressure was applied. The Skempton's $B$ values obtained were greater than 0.95 .

Then, the samples were isotropically consolidated to the value of effective mean pressure $p^{\prime}{ }_{c}$ of about $310 \mathrm{kPa}$ in the case of undrained tests no $12-2,12-3,12-3 \mathrm{f}$ and $114 \mathrm{kPa}$ in case of test $12-3 \mathrm{~g}$.

Table 1. Values of some physical properties and classification characteristics of Tułowice kaolin (Jastrzębska [9])

\begin{tabular}{lccclccc}
\hline Specific gravity & $\mathrm{G}_{\mathrm{s}}$ & $\mathrm{t} / \mathrm{m}^{3}$ & 2.637 & Void ratio & $\mathrm{e}$ & - & $0.956-1.098$ \\
\hline Natural water content & $\mathrm{w}_{\mathrm{n}}$ & $\%$ & 20.7 & Clay fraction & $\mathrm{CF}$ & $\%$ & $37.0-37.9$ \\
\hline Liquid limit & $\mathrm{w}_{\mathrm{L}}$ & $\%$ & 42.2 & Silt-size fraction & $\mathrm{SF}$ & $\%$ & $53.7-56.3$ \\
\hline Plastic limit & $\mathrm{w}_{\mathrm{p}}$ & $\%$ & 20.0 & Effective cohesion & $\mathrm{c}$ & $\mathrm{kPa}$ & 10.7 \\
\hline Plasticity index & $\mathrm{I}_{\mathrm{p}}$ & $\%$ & 22.2 & $\begin{array}{l}\text { Effective angle of } \\
\text { internal friction }\end{array}$ &, & & 25 \\
\hline Liquidity index & $\mathrm{I}_{\mathrm{L}}$ & - & 0.03 & Poisson's ratio & & & 0.085 \\
\hline Skempton's coefficient & $\mathrm{A}$ & - & $0.52-0.6$ & & & \\
\hline
\end{tabular}

Next, two of the chosen soil samples were unloaded to effective pressures $p^{\prime}{ }_{0}$ of about $110 \mathrm{kPa}$ (tests 12-3 and 12-3f). This value corresponds to the overconsolidation ratio equal to $O C R=\mathrm{p}^{\prime} \mathrm{c}_{\mathrm{p}}{ }_{0}$ $=2.8$. After isotropic consolidation undrained tests were carried out.

Details of tests' conditions are specified in Table 2.

\subsection{Laboratory tests}

After completed saturation and consolidation, cyclic triaxial tests were started in conditions of water drainage prevented from the sample, according to the assumed testing procedure (Table 2, Figs. 1 and 2). The value of deviator stress amplitude $A$ is the most important criterion for all tests' division. „Unloading - reloading” cycles were carried out after achieving during monotonous loading of axial strain ${ }_{l}=1.5 \%$ (tests $12-2$ and $12-3$ ) or consecutively ${ }_{l}=0.5,1.0$ and $1.5 \%$ (tests $12-3 \mathrm{f}$ and $12-3 \mathrm{~g}$ ).

An example of cyclic loading at constant amplitude (tests 12-2 and 12-3) and of decreasing or constant, but stepwise changing amplitude, at one or a few levels of deviator stress was represented experimentally in as simple as possible way. The last two cases were considered within combined series during one test (tests 12-3f and 12-3g), with clearly distinguished case of decreasing amplitude (series of eight cycles starting at strain ${ }_{l}=0.5 \%$ ). 
Because of instrument capabilities, the starting point - conditioning the beginning of cyclic load action - consists of current axial strain and corresponding at specific moment deviator stress, against which the amplitude value is determined. Characteristic value of axial strain was assumed to be 1, unload $=1.5 \%$ (tests $12-2$ and $12-3$ ) and ${ }_{1, \text { unload }}=0.5 \%$ (tests $12-3 \mathrm{f}$ and $12-3 \mathrm{~g}$ ).

Figs. 1 and 2 show schemes, according to which individual tests were carried out. They present the number and arrangement of cycles $(n)$, amplitude size $\left(A_{i}\right)$ including its upper and lower bound, the axial strain value initiating the cyclic loading $(1$, unload $)$ and corresponding deviator stress value $\left(q_{i}\right)$. Assuming denotations $q_{0.5 \%}, q_{1.0 \%}, q_{1.5 \%}$ and $q_{3.0 \%}$, i.e. the deviator stress value at vertical strain equal to ${ }_{l}=0.5 \%,{ }_{l}=1.0 \%$ and ${ }_{l}=1.5 \%$ respectively, the load amplitude value was defined as: $\boldsymbol{A}_{\boldsymbol{I}}=0.75 \mathrm{q} \Rightarrow\left(\boldsymbol{A}_{1, \boldsymbol{I}}=0.5 \mathrm{~A}_{1}=0.375 \mathrm{q}_{0.5 \%}, \boldsymbol{A}_{1,2}=0.75 \mathrm{~A}_{1}=0.563 \mathrm{q}_{0.5 \%}, \boldsymbol{A}_{\boldsymbol{1}, 3}=0.8 \mathrm{~A}_{1}=0.6 \mathrm{q}_{0.5 \%}\right.$, $\left.\boldsymbol{A}_{1,4}=1.2 \mathrm{~A}_{1}=0.9 \mathrm{q}_{0.5 \%}\right)$ and $\boldsymbol{A}_{2}=0.75 \mathrm{q}_{1.5 \%} \quad \Rightarrow \boldsymbol{A}_{2,1}=0.5 \mathrm{~A}_{2}=0.375 \mathrm{q}_{1.5 \%}$.

The soil specimens' shear was performed at a constant strain rate (strain controlled) equal to $\mathrm{v}=0.22 \mathrm{~mm} / \mathrm{h}$.

Table 2. Characteristics of tests carried out within the study

\begin{tabular}{|c|c|c|c|c|c|c|c|c|c|c|}
\hline 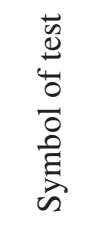 & 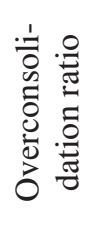 & 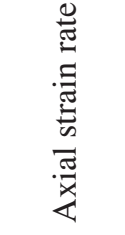 & 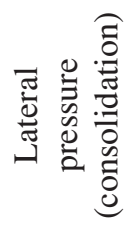 & 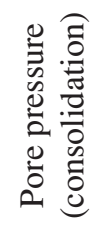 & 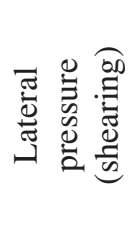 & 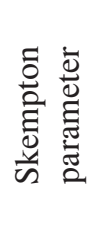 & 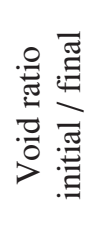 & 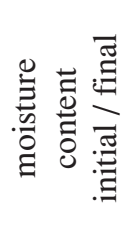 & 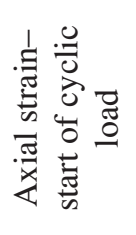 & 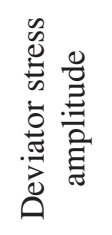 \\
\hline & OCR & $\mathrm{v}$ & 3 & $\mathrm{u}_{\mathrm{b}}$ & 3 & B & $\mathrm{e}_{0} / \mathrm{e}_{\mathrm{k}}$ & $\mathrm{w}_{0} / \mathrm{w}_{\mathrm{k}}$ & 1 ,unload & A \\
\hline & & {$[\mathrm{mm} / \mathrm{h}]$} & {$[\mathrm{kPa}]$} & {$[\mathrm{kPa}]$} & {$[\mathrm{kPa}]$} & {$[-]$} & {$[-]$} & [\%] & [\%] & {$[-]$} \\
\hline $\begin{array}{l}12-2 \\
\text { CIU }\end{array}$ & 1 & $\begin{array}{c}0.22 \\
\mathrm{v} 6\end{array}$ & 308 & 442 & 308 & $\begin{array}{c}0.98 \\
(450) \\
\end{array}$ & $\begin{array}{l}1.098 \\
0.810\end{array}$ & $\begin{array}{l}37.73 \\
28.34\end{array}$ & 1.5 & $\begin{array}{c}0.75 \mathrm{q} \\
\text { sch. } 1\end{array}$ \\
\hline $\begin{array}{l}12-3 \\
\text { CIU }\end{array}$ & 2.8 & 0.22 & $\begin{array}{l}309 \\
110 \\
\end{array}$ & 441 & 110 & $\begin{array}{c}0.98 \\
(450)\end{array}$ & $\begin{array}{l}1.041 \\
0.861 \\
\end{array}$ & $\begin{array}{l}35.73 \\
29.25 \\
\end{array}$ & 1.5 & $\begin{array}{l}0.75 \text { q } \\
\text { sch. } 1\end{array}$ \\
\hline $\begin{array}{l}12-3 f \\
\text { CIU }\end{array}$ & 2.8 & 0.22 & $\begin{array}{l}315 \\
115\end{array}$ & 435 & 115 & $\begin{array}{c}0.95 \\
(450)\end{array}$ & $\begin{array}{l}0.958 \\
0.776\end{array}$ & $\begin{array}{l}34.94 \\
29.36\end{array}$ & $\begin{array}{l}0.5 \\
1.0 \\
1.5 \\
\end{array}$ & $\begin{array}{c}\text { sch. } \\
\text { of } \\
\text { cycles }\end{array}$ \\
\hline $\begin{array}{c}12-3 \mathrm{~g} \\
\mathrm{CIU}\end{array}$ & 1 & 0.22 & 114 & 436 & 114 & $\begin{array}{c}0.95 \\
(450)\end{array}$ & $\begin{array}{l}0.956 \\
0.865\end{array}$ & $\begin{array}{l}35.67 \\
31.78\end{array}$ & $\begin{array}{l}0.5 \\
1.0 \\
1.5\end{array}$ & $\begin{array}{c}\text { sch. } \\
\text { of } \\
\text { cycles }\end{array}$ \\
\hline
\end{tabular}

Tables 3 and 4 specify for individual cycles the relations $G_{\text {int }} / G_{\text {ext }}$ estimated in characteristic points, from the point of stiffness distribution view, i.e. $\quad l=0.00005,0.0001$ and 0.001 . Moreover, the value of linearity factor $L$ acc. to relation (2) was determined:

$$
L=\frac{G_{10^{3}}}{G_{10^{4}}}
$$

For comparison, pairs of tests were selected, subject to the same cycles of loading acc. to scheme I and II, but differing in the value of overconsolidation ratio $(O C R=1$ and 2.8 for [12-2 and 12-3] and [12-3f and 12-3g], respectively). 


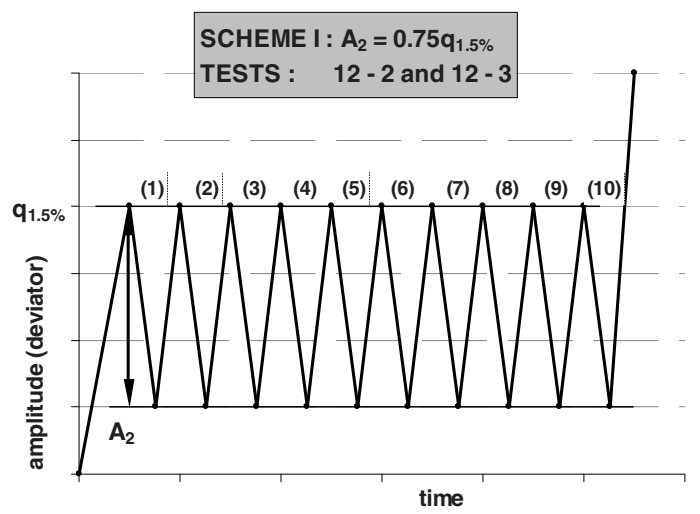

Fig. 1. Scheme I of cyclic load at constant amplitude (10 cycles, $\left.A_{2}=0.75 \mathrm{q}_{1.5 \%}\right)$

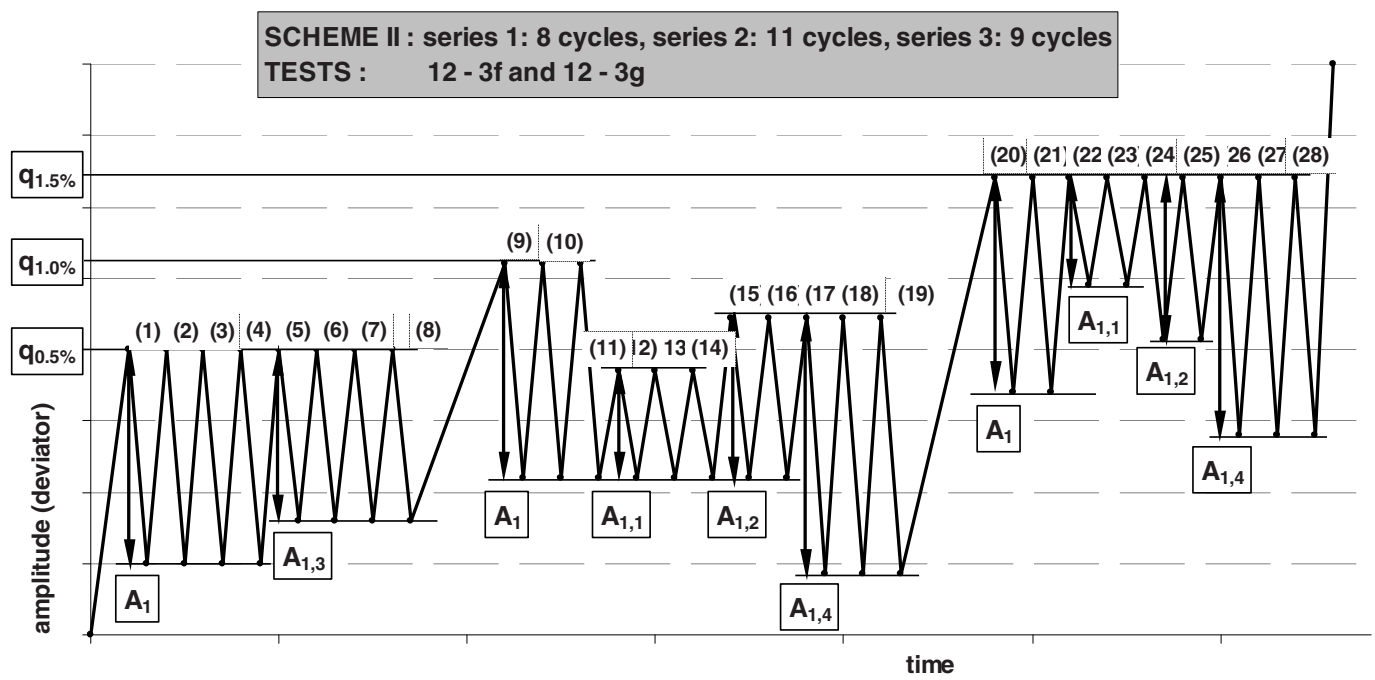

Fig. 2. Scheme II of cyclic load at variable amplitude. Series $1: A_{l}=0.75 \mathrm{q}_{0.5 \%}$ and $A_{1,3}=0.6 \mathrm{q}_{0.5 \%}$; series 2 and 3: $A_{l}=0.75 \mathrm{q}_{0.5 \%}, A_{l, 1}=0.375 \mathrm{q}_{0.5 \%}, A_{l, 2}=0.563 \mathrm{q}_{0.5 \%}$, and $A_{1,4}=0.9 \mathrm{q}_{0.5 \%}$ 
Table 3. Comparison of undrained triaxial tests results $(12-2, O C R=1$ and $12-3, O C R=2.8)$ with internal and external measurement

\begin{tabular}{|c|c|c|c|c|c|c|c|c|c|c|}
\hline \multirow{5}{*}{ 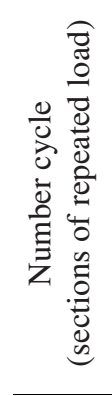 } & \multicolumn{5}{|c|}{$12-2$} & \multicolumn{5}{|c|}{$12-3$} \\
\hline & \multicolumn{5}{|c|}{$\begin{array}{c}\mathrm{OCR}=1, \quad{ }_{3}=308 \mathrm{kPa}, \mathrm{v}=0.22 \mathrm{~mm} / \mathrm{h} \\
1, \text { unload }=1.5 \% \text {, sch. I: } \mathrm{A}=0.75 \mathrm{q}\end{array}$} & \multicolumn{5}{|c|}{$\begin{aligned} \mathrm{OCR}=2.8, \quad{ }^{\prime}=109 \mathrm{kPa}, \mathrm{v} & =0.22 \mathrm{~mm} / \mathrm{h} \\
1, \text { unload } & =1.5 \%, \text { sch. I: } \mathrm{A}=0.75 \mathrm{q}\end{aligned}$} \\
\hline & \multicolumn{3}{|c|}{$\mathbf{G}_{\text {int }} / \mathbf{G}_{\text {ext }}$} & \multirow{2}{*}{\multicolumn{2}{|c|}{$\mathrm{L}=\mathrm{G}_{0.001} / \mathrm{G}_{0.0001}$}} & \multicolumn{3}{|c|}{$\mathbf{G}_{\mathrm{int}} / \mathbf{G}_{\mathrm{ext}}$} & \multirow{2}{*}{\multicolumn{2}{|c|}{$\mathrm{L}=\mathrm{G}_{0.001} / \mathrm{G}_{0.0001}$}} \\
\hline & \multicolumn{3}{|c|}{${ }_{1}[-]$} & & & \multicolumn{3}{|c|}{${ }_{1}[-]$} & & \\
\hline & 0.00005 & 0.0001 & 0.001 & $\mathbf{L}_{\text {int }}$ & $\mathbf{L}_{\text {ext }}$ & 0.00005 & 0.0001 & 0.001 & $\mathbf{L}_{\text {int }}$ & $\mathbf{L}_{\text {ext }}$ \\
\hline 1 & \begin{tabular}{|l|}
2.35 \\
\end{tabular} & 1.41 & 1.07 & 0.23 & 0.30 & 3.11 & 2.10 & 1.06 & 0.21 & 0.41 \\
\hline 2 & 2.35 & 1.37 & 1.04 & 0.22 & 0.28 & 3.75 & 2.76 & 1.06 & 0.19 & 0.50 \\
\hline 3 & 2.47 & 1.66 & 1.02 & 0.21 & 0.34 & 3.50 & 2.60 & 1.13 & 0.20 & 0.47 \\
\hline 4 & 2.54 & 1.79 & 1.02 & 0.18 & 0.32 & 3.50 & 2.16 & 1.06 & 0.22 & 0.44 \\
\hline 5 & 2.54 & 1.89 & 1.02 & 0.16 & 0.30 & 2.68 & 1.79 & 1.03 & 0.24 & 0.43 \\
\hline 6 & 2.57 & 1.95 & 1.02 & 0.16 & 0.30 & 4.07 & 2.38 & 1.06 & 0.23 & 0.52 \\
\hline 7 & 2.50 & 2.02 & 1.02 & 0.15 & 0.29 & 4.27 & 2.46 & 1.06 & 0.24 & 0.56 \\
\hline 8 & 2.69 & 2.05 & 1.02 & 0.14 & 0.27 & 4.69 & 2.50 & 1.06 & 0.19 & 0.46 \\
\hline 9 & 2.77 & 2.08 & 1.02 & 0.13 & 0.27 & 5.24 & 3.46 & 1.06 & 0.19 & 0.63 \\
\hline 10 & 2.91 & 2.15 & 1.02 & 0.13 & 0.28 & 5.11 & 4.00 & 1.09 & 0.21 & 0.76 \\
\hline
\end{tabular}

Table 4. Comparison of undrained triaxial tests results $(12-3 \mathrm{~g}, O C R=1$ and $12-3 \mathrm{f}, O C R=2.8)$ with internal and external measurement

\begin{tabular}{|c|c|c|c|c|c|c|c|c|c|c|}
\hline \multirow{5}{*}{ 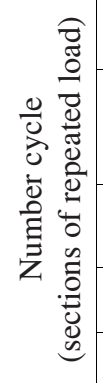 } & \multicolumn{5}{|c|}{$12-3 g$} & \multicolumn{5}{|c|}{$12-3 f$} \\
\hline & \multicolumn{5}{|c|}{$\begin{array}{r}\mathrm{OCR}=1.0, \quad{ }^{\prime}=114 \mathrm{kPa}, \mathrm{v}=0.22 \mathrm{~mm} / \mathrm{h} \\
\text { sch. II: } \quad{ }_{1, \text { unload }}=0.5 / 1.0 / 1.5 \%\end{array}$} & \multicolumn{5}{|c|}{$\begin{array}{r}\mathrm{OCR}=2.8, \quad{ }_{3}=114 \mathrm{kPa}, \mathrm{v}=0.22 \mathrm{~mm} / \mathrm{h} \\
\text { sch. II: } \quad{ }_{1, \text { unload }}=0.5 / 1.0 / 1.5 \%\end{array}$} \\
\hline & \multicolumn{3}{|c|}{$\mathbf{G}_{\text {int }} / \mathbf{G}_{\text {ext }}$} & \multirow{2}{*}{\multicolumn{2}{|c|}{$\mathrm{L}=\mathrm{G}_{0.001} / \mathrm{G}_{0.0001}$}} & \multicolumn{3}{|c|}{$\mathbf{G}_{\text {int }} / \mathbf{G}_{\text {ext }}$} & \multirow{2}{*}{\multicolumn{2}{|c|}{$\mathrm{L}=\mathrm{G}_{0.001} / \mathrm{G}_{0.0001}$}} \\
\hline & \multicolumn{3}{|c|}{${ }_{1}[-]$} & & & \multicolumn{3}{|c|}{${ }_{1}[-]$} & & \\
\hline & 0.00005 & 0.0001 & 0.001 & $\mathbf{L}_{\text {int }}$ & $\mathbf{L}_{\mathrm{ext}}$ & 0.00005 & 0.0001 & 0.001 & $\mathbf{L}_{\text {int }}$ & $\mathbf{L}_{\text {ext }}$ \\
\hline 1 & 1.15 & - & - & - & - & 1.50 & 1.23 & - & - & - \\
\hline 2 & 1.00 & - & - & - & - & 1.36 & 1.12 & - & - & - \\
\hline 3 & 0.98 & - & - & - & - & 1.17 & 1.07 & - & - & - \\
\hline 4 & 1.05 & - & - & - & - & 1.43 & 1.25 & - & - & - \\
\hline 5 & - & - & - & - & - & 1.05 & 1.21 & - & - & - \\
\hline 6 & - & - & - & - & - & 1.00 & 1.04 & - & - & - \\
\hline 7 & - & - & - & - & - & 1.00 & 1.01 & - & - & - \\
\hline 8 & 1.05 & 1.04 & 1.00 & 0.10 & 0.10 & 1.07 & 1.09 & 1.03 & 0.11 & 0.12 \\
\hline
\end{tabular}


Table 4. (continuation)

\begin{tabular}{c|ccc|cc|ccc|cc}
\hline 9 & 1.10 & - & - & - & - & 1.14 & 1.13 & - & - & - \\
\hline 10 & 1.02 & - & - & - & - & 1.03 & 1.02 & - & - & - \\
\hline 11 & - & - & - & - & - & - & - & - & - & - \\
\hline 12 & - & - & - & - & - & - & - & - & - & - \\
\hline 13 & - & - & - & - & - & - & - & - & - & - \\
\hline 14 & - & - & - & - & - & 1.23 & 1.08 & - & - & - \\
\hline 15 & - & - & - & - & - & 1.17 & 1.05 & - & - & - \\
\hline 16 & 0.70 & - & - & - & - & 1.02 & 1.03 & - & - & - \\
\hline 17 & 1.46 & - & - & - & - & 1.63 & 1.37 & - & - & - \\
\hline 18 & 1.16 & 1.12 & - & - & - & 1.39 & 1.13 & - & - & - \\
\hline 19 & 1.23 & 1.15 & 1.04 & 0.12 & 0.14 & 1.28 & 1.19 & 1.00 & 0.20 & 0.23 \\
\hline 20 & - & - & - & - & - & 1.33 & 1.21 & - & - & - \\
\hline 21 & 1.00 & - & - & - & - & 1.17 & 1.19 & - & - & - \\
\hline 22 & - & - & - & - & - & - & - & - & - & - \\
\hline 23 & - & - & - & - & - & - & - & - & - & - \\
\hline 24 & - & - & - & - & - & 1.33 & - & - & - & - \\
\hline 25 & - & - & - & - & - & 1.25 & 1.03 & - & - & - \\
\hline 26 & 0.98 & 1.04 & - & - & - & 1.20 & 1.07 & - & - & - \\
\hline 27 & 1.16 & 1.14 & - & - & - & 1.28 & 1.18 & - & - & - \\
\hline 28 & 1.10 & 1.05 & - & 0.14 & 0.14 & 1.12 & 1.06 & - & 0.16 & 0.17 \\
\hline
\end{tabular}

Based on the results obtained the following conclusions may be drawn:

1. For each cycle, on all levels of strain ${ }_{1}$, the value of ratio $G_{\text {int }} / G_{\text {ext }}$ for overconsolidated soils is higher than for normally consolidated soils, where the differences diminish with increasing strain.

$\left.\left.\left.\operatorname{cycles}\left(\begin{array}{cc}1 & 10 \\ 1 & 28\end{array}\right) \quad\left[\left(\frac{G_{\text {int }}}{G_{\text {ext }}}\right)_{1=0.00005}^{O C}\right\rangle\left(\frac{G_{\text {int }}}{G_{\text {ext }}}\right)_{1=0.00005}^{N C}\right]\right\rangle\left[\left(\frac{G_{\text {int }}}{G_{\text {ext }}}\right)_{1=0.001}^{O C}\right\rangle\left(\frac{G_{\text {int }}}{G_{\text {ext }}}\right)_{1=0.001}^{N C}\right]$

2. In the case of a series of equal amplitude cycles, irrespective of the $O C R$ coefficient, on all levels of strain ${ }_{1}$, the value of ratio $G_{i n t} / G_{\text {ext }}$ for the first cycle is smaller than for the last (10) cycle, where the differences become smaller with increasing strain and are less significant for normally consolidated soils.

$\underbrace{N C \& O C \text { soils }}_{(12 \text { 2) and }(12 \text { 3) }}\left[\left(\frac{G_{\text {int }}}{G_{\text {ext }}}\right)_{1=0.00005}^{1 c y c}\left\langle\left(\frac{G_{\text {int }}}{G_{\text {ext }}}\right)_{1=0.00005}^{10 c y c}\right]\right\rangle\left[\left(\frac{G_{\text {int }}}{G_{\text {ext }}}\right)_{1=0.001}^{1 c y c}\left\langle\left(\frac{G_{\text {int }}}{G_{\text {ext }}}\right)_{1=0.001}^{10 c y c}\right]\right.$

3. For identical cycles the values of linearity factor from internal measurements for normally consolidated soils $\left(\begin{array}{ll}L_{\text {int }} & 0.19\end{array}\right)$ are smaller than for overconsolidated soils $\left(\begin{array}{ll}L_{\text {int }} & 0.21\end{array}\right)$, but the differences are much smaller than for external readings $\left(L_{\text {ext }} \quad 0.29\right.$ and 0.53$)$. However, at many series of different cycles values $L$ from internal ( $L_{\text {int }} \quad 0.12$ for $\mathrm{NC}$ and 0.16 for OC) and external ( $L_{e x t} \quad 0.13$ for NC and 0.17 for OC) measurements are close to each other. 


$$
\begin{aligned}
& \operatorname{cycles}(1-10) \quad\left[L_{\text {int }}^{N C}<L_{\text {int }}^{O C}\right\rfloor<\left\lfloor L_{\text {ext }}^{N C}<L_{\text {ext }}^{O C}\right\rfloor \\
& \underbrace{\operatorname{cycles}(1-28)}_{\text {int, } \text { ext }} \quad\left[L_{1 c y c}^{N C}<L_{28 c y c}^{N C}\right]<\left[L_{1 c y c}^{O C}<L_{28 c y c}^{O C}\right]
\end{aligned}
$$

\section{Summary}

A series of cyclic undrained triaxial tests (Jastrzębska and Sternik, [11]; Jastrzębska and Lupieżowiec, [12]) was carried out so far on the clay from Tułowice for the needs of the issue discussed. In this paper attention has been focused on the comparison of cohesive soil stiffness acc. to external and internal readings, and one of the adopted criteria for two measuring methods quality is the value of the linearity factor $L=G_{10}{ }^{3} / G_{10}{ }^{4}$ (suggested by Jardine et al., [9]), which shows the course of stiffness curves, its „steepness”, i.e. the nature of stiffness modulus changes in the area of small strains. The comparison of obtained values of $G_{i n t}$ and $G_{\text {ext }}$ (or $L_{\text {int }}$ and $L_{\text {ext }}$ ) clearly shows an obvious underestimation (even 5 times) of shear moduli values within the range $10^{-5} \div 10^{-3}$ when using an external measurement.

The comparative analysis comprises carried out additionally parametric study of the influence of various cyclic process parameters: deviator stress amplitude (constant or variable; high or low), initial stress level and strain, at which unloading and reloading cycles were started, overconsolidation ratio $O C R$ and cycles' number and arrangement on the ,shear modulus - axial strain" characteristics. Taking this into account, the differences between $G_{\text {int }}$ and $G_{\text {ext }}$ develop differently depending on the aforementioned parameters. However, with increasing axial strains these differences gradually disappear.

\section{References}

1. Kriegel H.J., Weisner H.H., Proc. 8th ICSMFE, 1.3, (1973) 133-141

2. Burland J.B., Canadian Geotechnical Journal, 26, (1989) 499-516

3. Jardine R.J., Soils and Foundations, 32 (2), (1992) 111-124

4. Rampello S. Proc. of the International Workshop on "Experimental Characterization and Modelling of Soils and Soft Rocks", Napoli (Italy), (1991) 131-190

5. Rampello S., Pane V. Atti del Convegno sul tema: Deformazioni dei Terreni ed Inetrazione Terreno-Struttura in Condizioni di Esercizio, CNR, Monselice, (1988) 141-160

6. Georgiannou V.N., Rampello S., Silvestri F., Proc. 10th ECSMFE, Firence, 1, (1991) 91-95

7. Costafilho L.M., A laboratory investigation of the small strain behaviour of London Clay, $\mathrm{Ph}$. D. Thesis, University of London, (1980)

8. Daramola O., The influence of stress history on the deformation of sand, $\mathrm{Ph}$. D. Thesis, University of London, (1978)

9. Jardine R.J., Symes M.J., Bourland J.B., Géotechnique, 34 (3), (1984) 323-340

10. Jastrzębska M., Calibration and verification of one-surface elasto-plastic soil model of strongly non-linear anisotropic strengthening, Ph.D. Thesis, Silesian University of Technology, Gliwice, (in polish) (2002)

11. Jastrzębska M., Sternik K., Int. Conference on „Cyclic behaviour of soils and liquefaction phenomena", Bochum - Germany, (2004) 41-46

12. Jastrzębska M., Łupieżowiec M., The 16th ICSMGE, Osaka, (2005) 807-810 